\title{
Oficina de fotografia de cena Olhar o teatro através da imagem
}

\author{
Filipe Figueiredo e Paula Magalhães
}

Para apresentar os resultados da investigação desenvolvida ao longo de três anos no âmbito do projecto OPSIS - Base Iconográfica de Teatro em Portugal, o Centro de Estudos de Teatro promoveu no passado mês de Março o colóquio "Imagens de uma ausência: Modos de (re)conhecimento do teatro através da imagem". 0 objectivo, a par da apresentação da plataforma online da base OPSIS, que em breve estará disponivel no sítio do CET da Faculdade de Letras da Uversidade do Porto, passava também por debater o contributo da imagem para o restauro do teatro ausente e para os modos de o conhecer.

Durante três dias estiveram reunidos quem estuda o teatro, quem o fixa através da fotografia e quem pensa o estatuto da imagem na cultura ocidental. Algumas das linhas orientadoras de um debate que envolveu investigadores, criadores, professores e até mesmo responsáveis por entidades detentoras de acervos de imagens foram: 0 (re)conhecimento de práticas teatrais através da imagem, o contributo da imagem como registo ou invenção do teatro, o olhar do fotógrafo, a resistência da matéria teatral e o sonho do historiador.

0 programa integrou também uma Oficina de fotografia de cena conduzida por Pedro Soares, fotógrafo que há mais de trinta anos acompanha as artes de palco, alguém que assume, de forma clara, a perspectiva de "servir o espectáculo e quem dele participa".

Ao longo de cinco dias, 12 formandos (Agnela de Barros, Gonçalo Barra, João Nuno Caseiro, José Manuel Furtado, Luisa Augusta de Sá, Maria da Conceição Agostinho, Nuno Alexandre Mota, Ricardo Reis, Rui Gregório, Ruth Rafaela, Sara Gouveia, Vitor Letras) receberam ensinamentos sobre como compreender as circunstâncias concretas do espectáculo teatral para dele poderem fazer uma eficaz fixação de imagem. 0 conceito de espectáculo, o estatuto do fotógrafo perante a cena, a análise das variáveis em torno da luz (fontes de luz, quantidade/qualidade, temperatura de cor, P\&tB e cor), o espaço cénico e a relação do fotógrafo com os intérpretes e outros agentes do espectáculo foram alguns dos temas abordados nesta oficina.
A par dos fundamentos teóricos, os participantes puderam captar imagens de três espectáculos diferentes, em condições bastante distintas: no decorrer de um ensaio para a imprensa do espectáculo A Cacatua Verde, de Arthur Schnitzler, em cena no D. Maria, (co-produção do Teatro da Cornucópia com o Teatro Nacional D. Maria II), no dia 14 de Fevereiro; durante o espectáculo E não se pode matá-los?, de Alicia Guerra, pelo e no Teatro da Comuna, no dia 16 de Fevereiro; e durante o aquecimento da actriz Elsa Valentim, antes do espectáculo Demónios de Macbeth, a partir de Shakespeare, uma produção do Teatro dos Aloés apresentada no Teatro da Trindade, no dia 17 de Fevereiro.

Algumas das centenas de fotografias reunidas foram apresentadas no último dia do colóquio, servindo de mote a um curto debate em torno de questões como o valor documental, artístico e expressivo das imagens e a eterna problematização sobre a fotografia de cena: quem deve servir e de que forma?

Aqui as imagens falam por si, apresentando diferentes olhares e perspectivas de quem, não sendo fotógrafo profissional, não quis deixar de mostrar as particularidades de uma modalidade com características muito específicas e que obriga a uma rigorosa disciplina.

0 sentir geral dos que disponibilizaram uma semana à apreensão do "saber fazer" associado à fotografia de cena aponta para ganhos em vários sentidos, nomeadamente no entendimento das especificidades técnicas, mas também artísticas, intrínsecas à captação da imagem de cena.

A experiência, vivida com grande entusiasmo, tem-se manifestado como terreno fértil para gerar novas inciativas, individuais ou a título colectivo.

Uma palavra de reconhecimento é devida ao fotógrafo Pedro Soares, pela forma empenhada como dirigiu esta oficina, assim como às companhias e aos seus actores, pela disponibilidade com que acolheram a Oficina de fotografia de cena e agora permitem a publicação de uma selecção dos seus resultados.
Filipe Figueiredo é Mestre em História da Arte pela Faculdade de Ciências Sociais e Humanas da Universidade Nova Lisboa, foi investigador do Projecto OPSIS e é, actualmente, Doutorando em Estudos de Teatro na Faculdade de Letras d Universidade de Lisboa

Paula Magalhães é Mestre em Estudos de Teatro pela Faculdade de Letras d Universidade de Lisboa, foi investigadora do Projecto OPSIS e é, actualmente, Doutoranda em Estudos de Teatro na mesma faculdade. 


\section{Legendas}

1| 2 | 3 | 4 | 5 | 6 | 7 | 8

\section{A Cacatua Verde,}

de Arthur Schnitzler,

enc. Luis Miguel Cintra,

Teatro da Cornucópia, 2011

1 > (Duarte Guimarães, Luis Miguel Cintra, Ricardo Aibéo, Tiago Matias, Sofia Marques, Vitor d'Andrade, José Manuel Mendes, Rita Blanco, Dinis Gomes, Miguel Loureiro, Nuno Casanovas, Cleia Almeida, Tobias Monteiro, Miguel Melo, Catarina Lacerda, Tiago Manaia, Gonçalo Amorim, Alice Medeiros, Neusa Dias Joana de Verona), fot. Ricardo Reis;

2 > (Gonçalo Amorim, Tiago Manaia, Miguel Melo, Cleia Almeida, Catarina Lacerda, Tiago Matias)

fot. Ricardo Reis;

3 > (João Grosso (deitado), Rita Loureiro, António Fonseca, Catarina Lacerda, Luis Miguel Cintra),

fot. Vitor Letras

4 > (Ricardo Aibéo, João Grosso, Rita Loureiro, Luis Miguel Cintra, António Fonseca, Tiago Manaia, Duarte Guimarães, Luis Lima Barreto (deitado), João Villas-Boas, Gonçalo Amorim, Joana de Verona, Rita Blanco, Neusa Dias, José Manuel Mendes, Dinis Gomes, Nuno Casanovas),

fot. Rui Gregório:

$5>$ (Rita Loureiro)

fot. Maria da Conceição Agostinho

$6>$ fot. Ricardo Reis;

7 > (Ricardo Aibéo, Luis Miguel Cintra, Gonçalo Amorim,

Tiago Manaia, Miguel Melo, Nuno Casanovas,

Catarina Lacerda)

fot. Nuno Alexandre Mota;

$8>$ (Nitor d'Andrade, Luis Miguel Cintra, Duarte Guimarães, António Fonseca, Miguel Melo, Tiago Matias,

Luis Lima Barreto (deitado)),

fot. Nuno Alexandre Mota.
$9|10| 11|12| 13|14| 15$

Demónios de Macbeth,

a partir de Macbeth, de Shakespeare,

enc. Sofia de Portugal,

Teatro dos Aloés, 2011

(Elsa Valentim)

$9>$ fot. João Nuno Caseiro:

$10>$ fot. Vitor Letras;

$11>$ fot. Ricardo Reis:

12 > fot. José Manuel Furtado;

$13>$ fot. Sara Gouveia

$14>$ fot. Nuno Alexandre Mota.

15 > fot. Gonçalo Barra;
$16|17| 18$ | $19|20| 21|22| 23|24| 25 \mid$ $26|27| 28$

Enãose pode matá-los,

de Alicia Guerra,

enc. João Mota,

Comuna - Teatro de Pesquisa, 2011

$16>$ (Álvaro Correia),

fot. Rui Gregório;

17 > (Carlos Paulo, Miguel Sermão)

fot. Sara Gouveia;

18 > (Álvaro Correia, Carlos Paulo), fot. José Manuel Furtado:

19 > (Álvaro Correia, Maria Ana Filipe, Joana Sapinho, Tânia Alves),

fot. José Manuel Furtado; 20 > (Tânia Alves, Maria Ana Filipe, Joana Sapinho, Álvaro Correia) fot Vitor Letras;

21 > (Tânia Alves, Maria Ana Filipe, Joana Sapinho, Álvaro Correia),

fot. Vitor Letras;

$22>$ (Maria Ana Filipe, Álvaro Correia)

fot. Rui Gregório;

$23>$ (Joana Sapinho)

fot. Ruth Rafaela;

24 >(Carlos Paulo, Álvaro Correia),

fot. Ruth Rafaela:

$25>$ (Maria Ana Filipe)

fot. Maria da Conceição Agostinho;

26 > (Maria Ana Filipe, Álvaro Correia)

fot. Ruth Rafaela;

27 > (Tânia Alves),

fot. José Manuel Furtado:

$28>$. (Álvaro Correia),

fot. Nuno Alexandre Mota. 


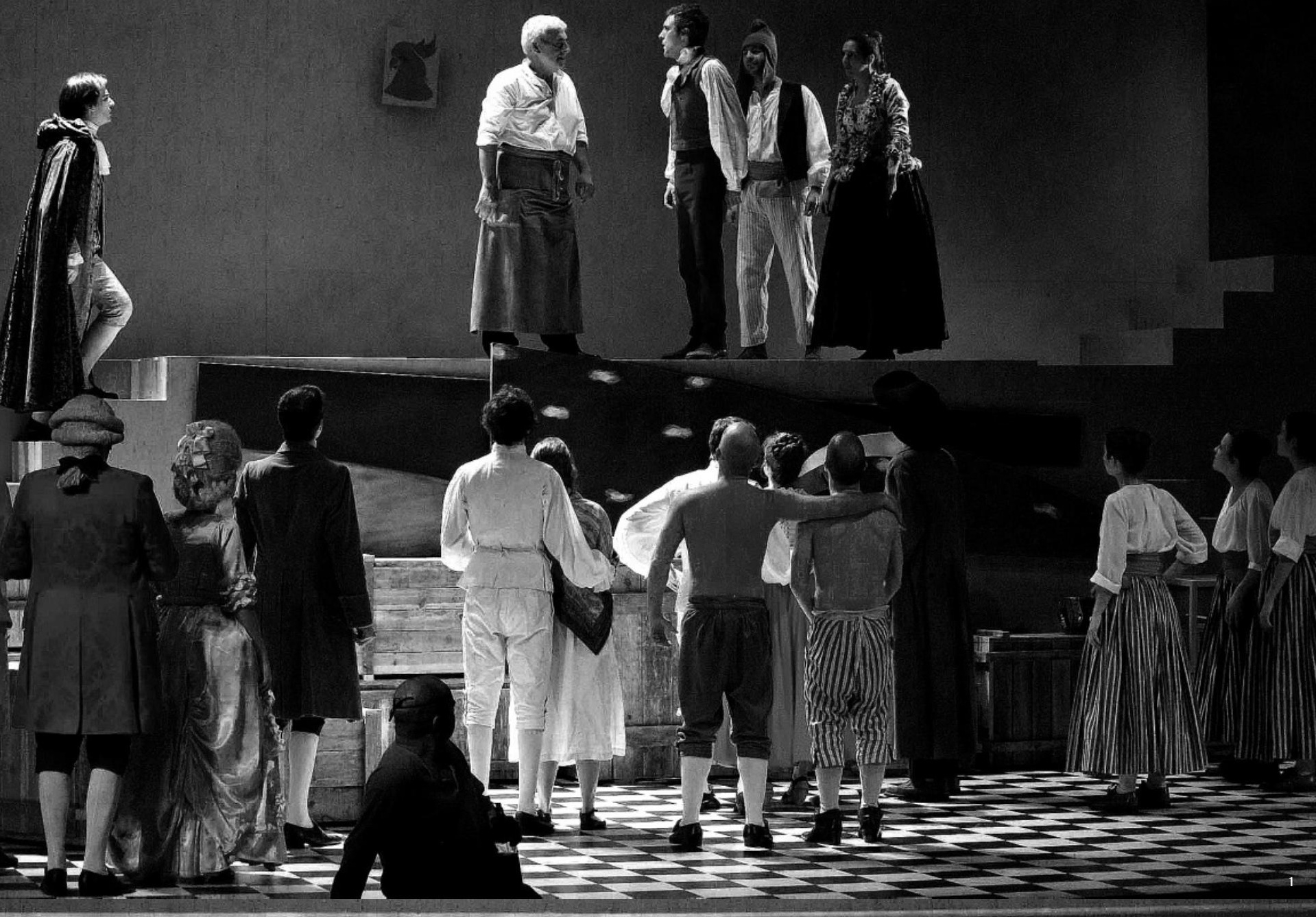




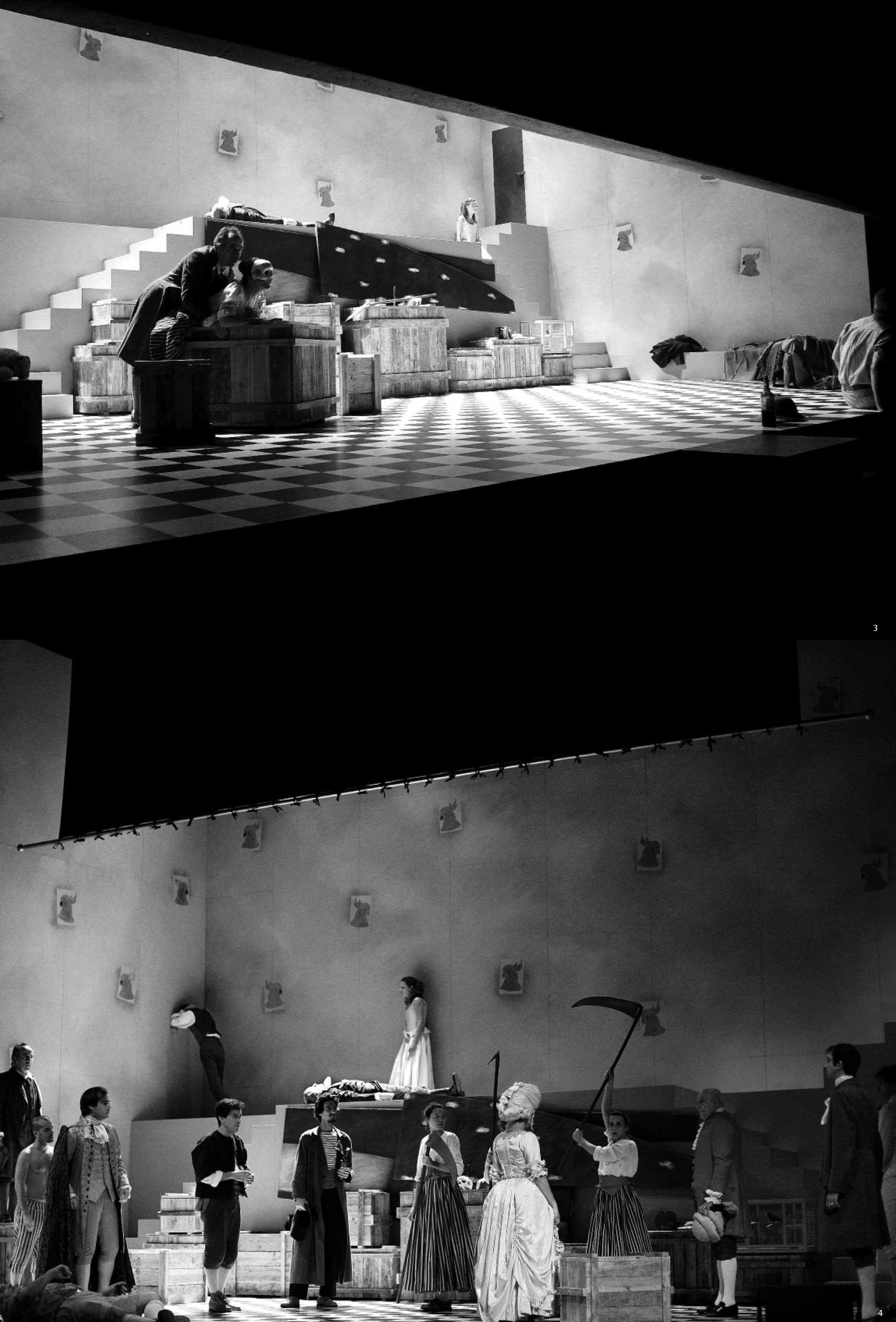



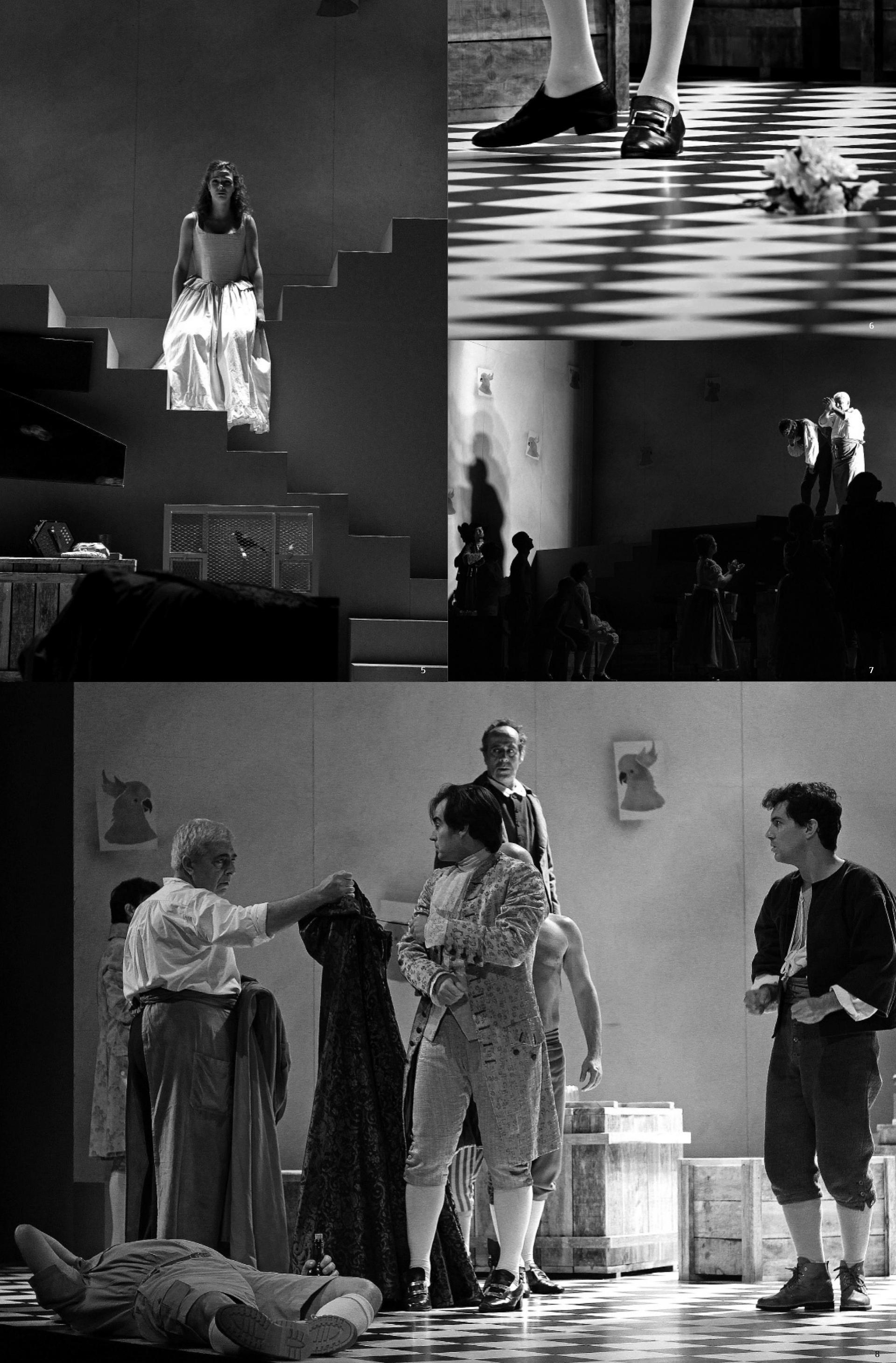


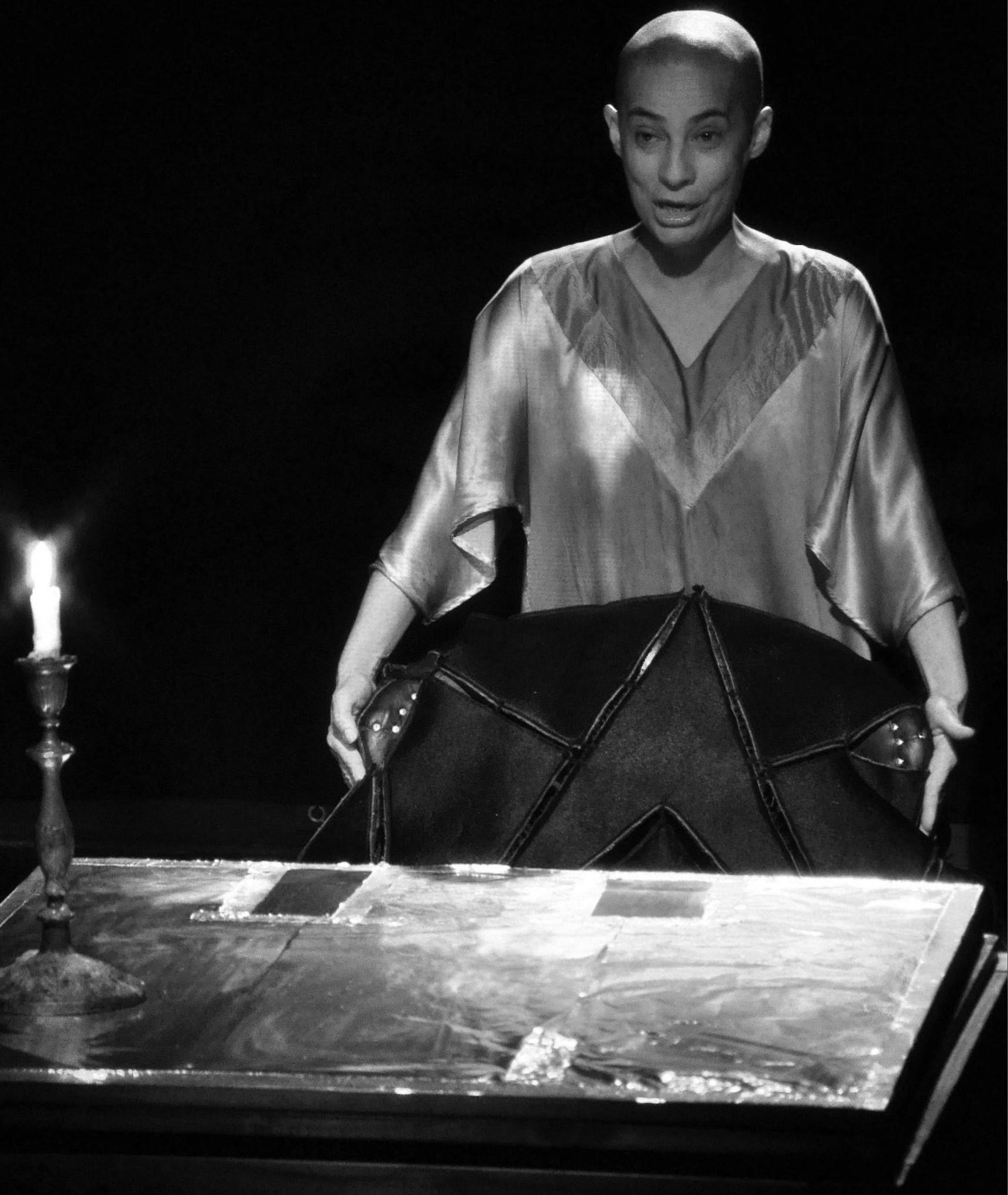




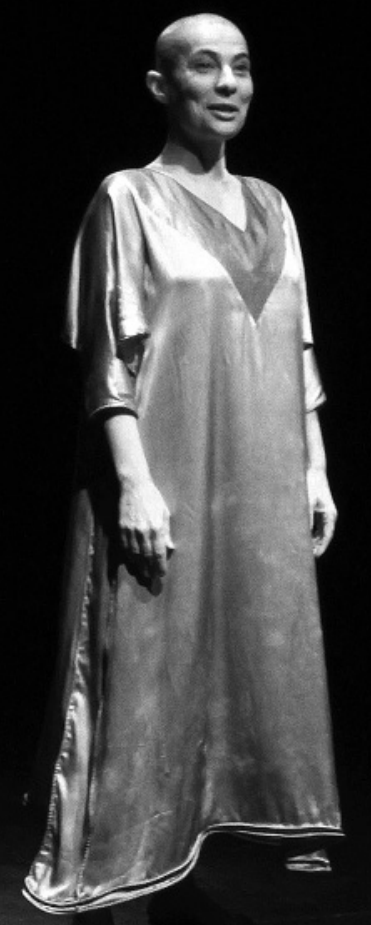

10
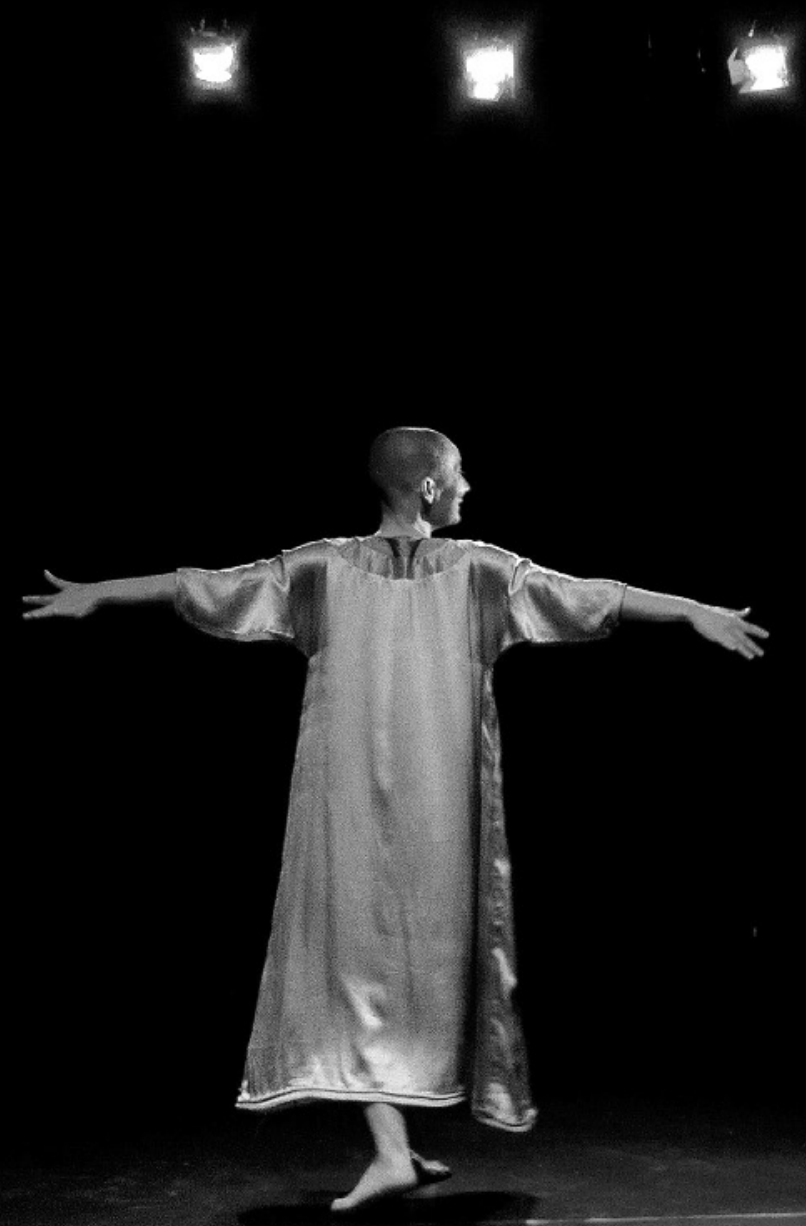
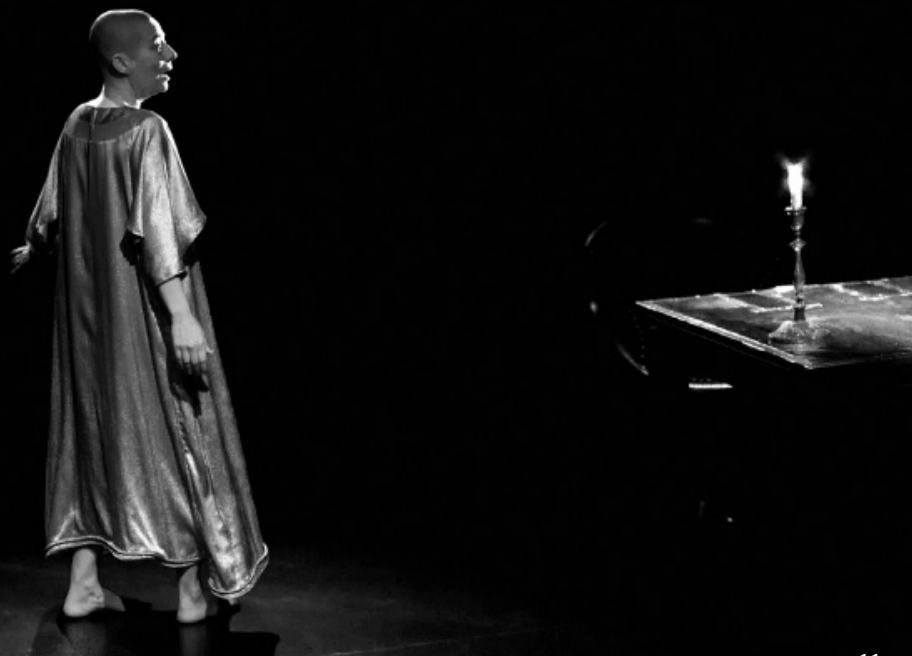

11

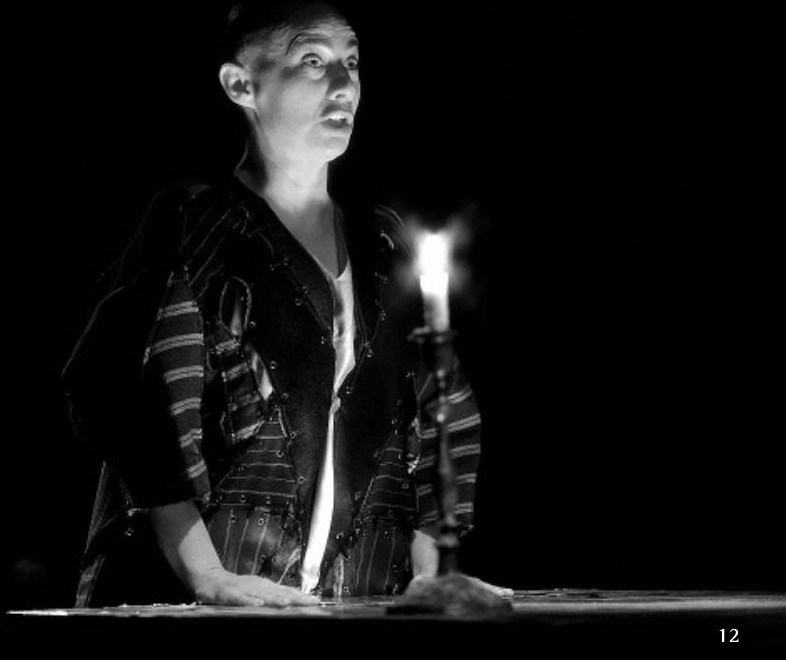

12

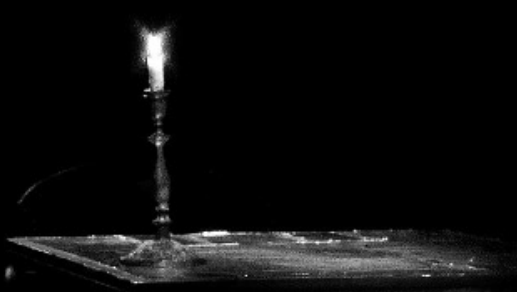



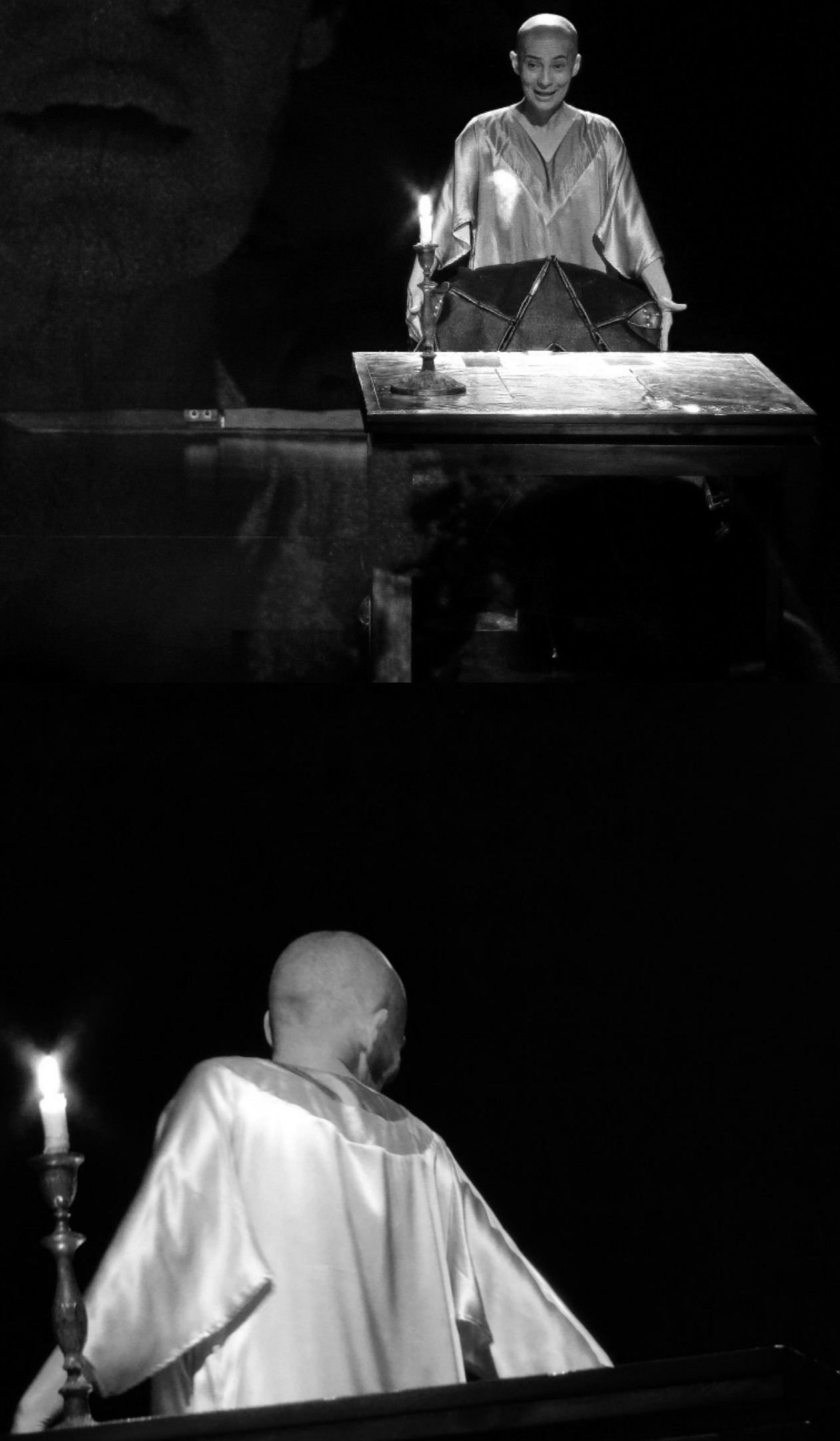

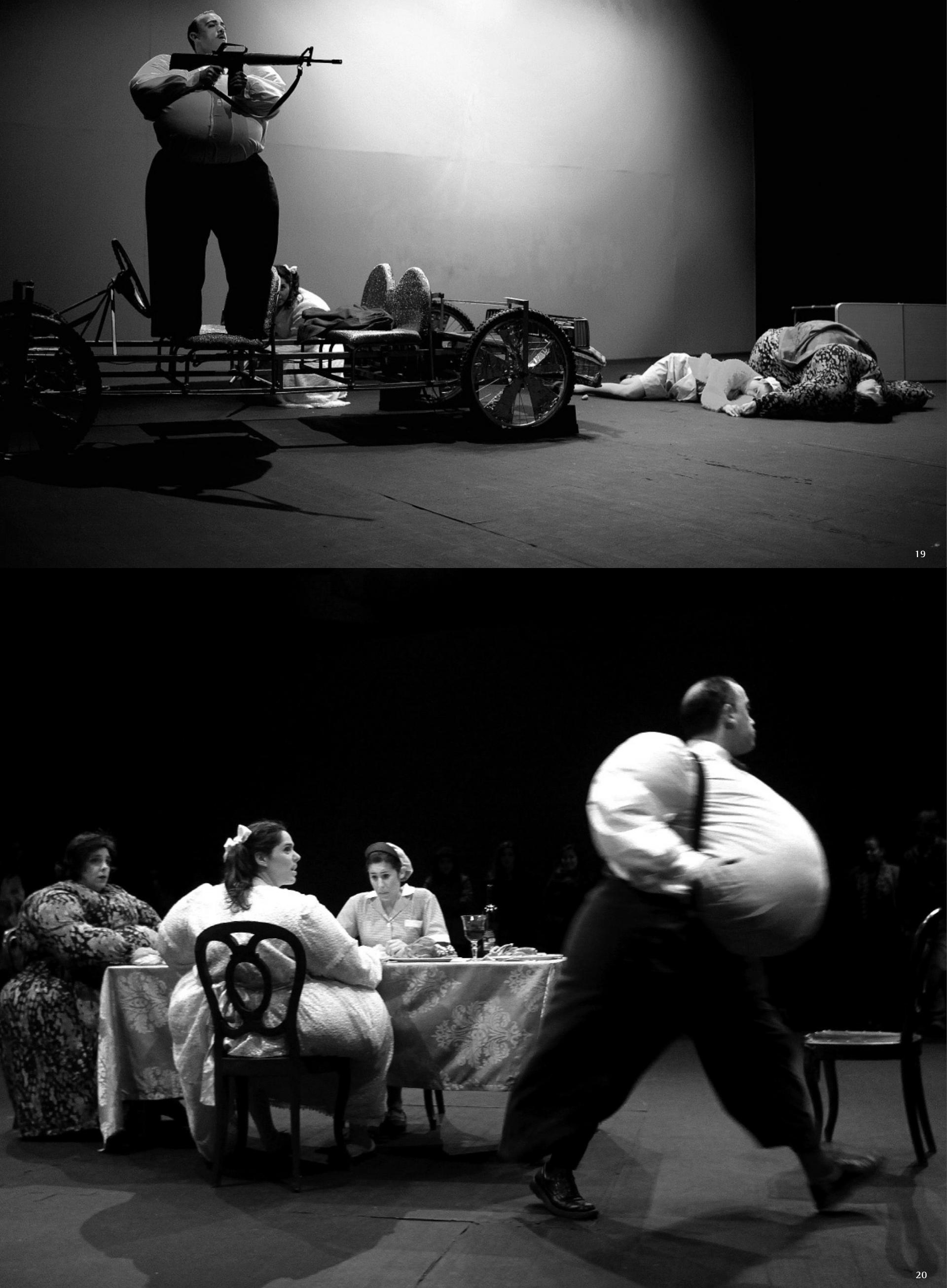

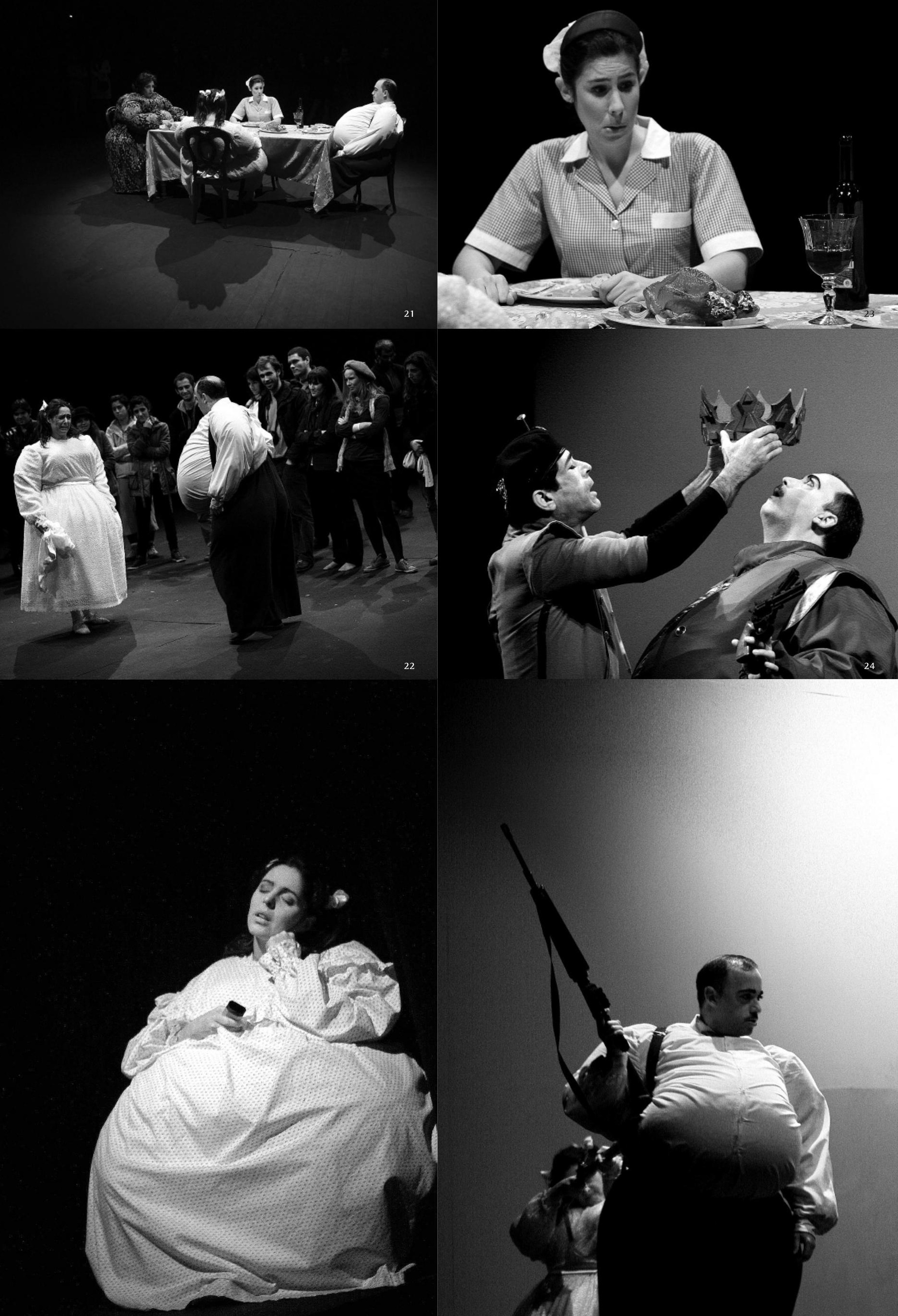

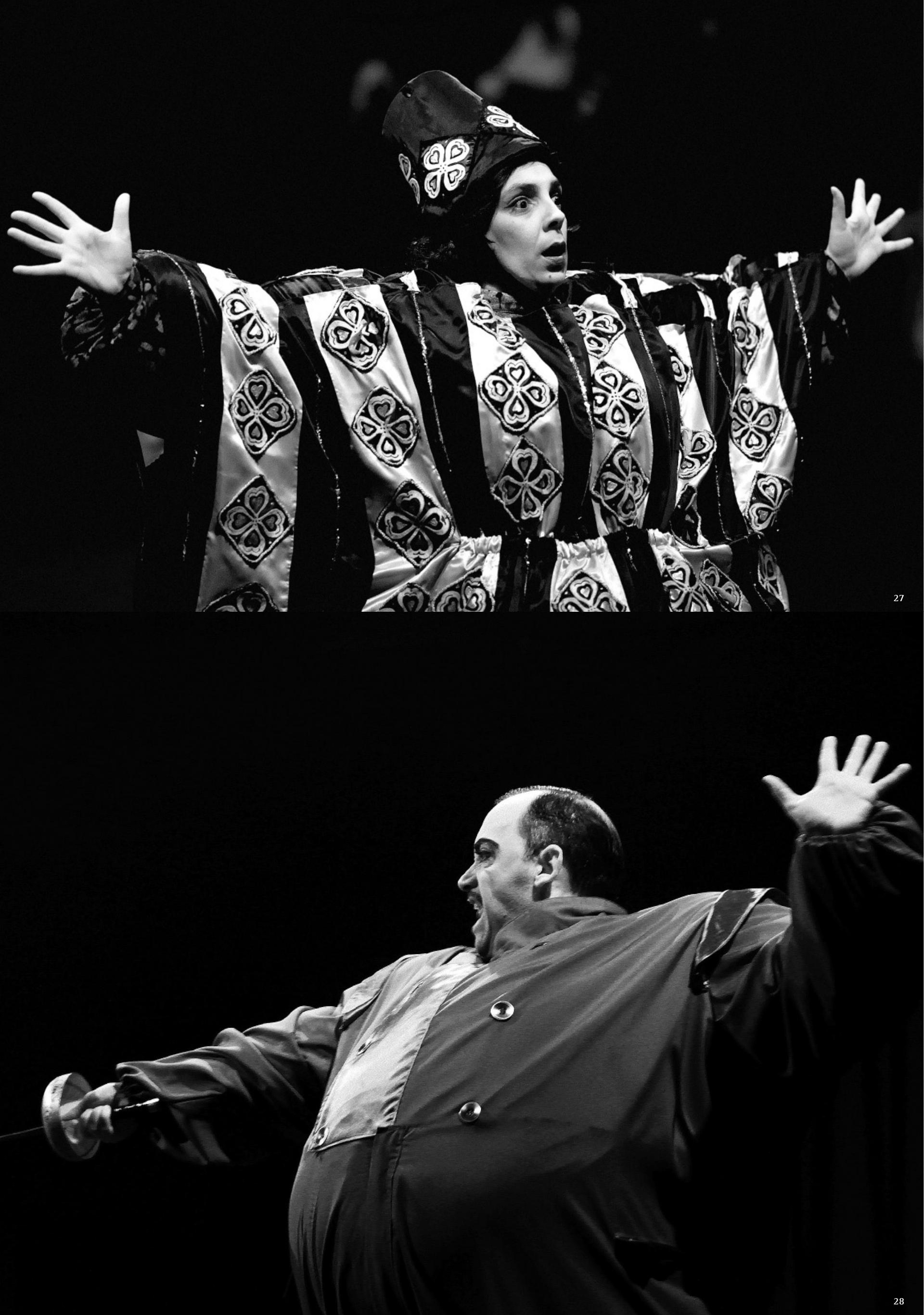